\title{
Computational and Statistical Analysis of Surface Temperature over Inhambane-Mozambique from 1931-2015: The Future Implications
}

\author{
M.E. Emetere ${ }^{1,2}$ \\ O.O. Fayomi ${ }^{1}$ \\ ${ }^{1}$ Covenant University Canaan land, P.M.B 1023, Ota, Nigeria \\ ${ }^{2}$ Department of Mechanical Engineering and Science, \\ University of Johannesburg, APK, South Africa
}

Doi: 10.36941/ajis-2020-0oo6

\section{Abstract}

The danger of the El Nino southern oscillation (ENSO) over tropical pacific might be heading for an all-time high. Eighty-five years (1931-2015) surface temperature dataset from Goddard Institute for Space Studies (GISS) over Inhambane-Mozambique were used for this study. The dataset was analyzed using the computational and statistical technique. The maximum monthly surface temperature that was recorded within eighty-five years was given as $16^{\circ} \mathrm{C}$ (January - 1990), $21.4{ }^{\circ} \mathrm{C}$ (February - 2006), 26.3 ${ }^{\circ} \mathrm{C}$ (March - 2010), $32 .{ }^{\circ} \mathrm{C}$ (April - 2010), $35.2{ }^{\circ} \mathrm{C}$ (May - 1978), $36.2{ }^{\circ} \mathrm{C}$ (June - 2012), $34.8^{\circ} \mathrm{C}$ (July - 2002), $32.4^{\circ} \mathrm{C}$ (August - 1987), $31.2{ }^{\circ} \mathrm{C}$ (September - 1987), $28.7^{\circ} \mathrm{C}$ (October - 1951), $22.1{ }^{\circ} \mathrm{C}$ (November - 1977 E 2011) and $17.6^{\circ} \mathrm{C}$ (December 2013). From the study, it was discovered that droughts over Mozambique and parts of Southern Africa were not caused by certain extreme ENSO. Rather, the drought was caused by series of continuous processes (extreme weather conditions) that influence certain atmospheric conditions.

Keyword: Surface temperature, weather conditions, climate change

\section{Introduction}

Surface temperature analysis could be associated with many events that are directly or indirectly contributive to its increase or decrease over the years. Climate change is the most influential of all direct factors that affects surface temperature. Estimating the role of climate change and its influence on the global mean surface temperature is very confusing i.e. looking at the accuracy level of measurement and validation of surface temperature data set. For example, $75 \%$ of the surface temperature dataset was missing around 1990 i.e. owing to bias towards higher-latitude and higheraltitude. Hence, the reality of the Earth's surface warming faster than the lower troposphere in the tropics maybe a major challenge on dataset validation.

The altitudinal temperature profile is very essential when considering dataset validation (Christy et al., 2000; Douglass et al., 2004). For example, two types of resolutions i.e. $1200 \mathrm{~km}$ and 250 $\mathrm{km}$ has shown global mean anomaly at $0.51^{\circ} \mathrm{C}$ and $0.44{ }^{\circ} \mathrm{C}$. Hansen et al. (2010) suggested that the $1200 \mathrm{~km}$ resolution analysis is more accurate for estimating anomalies in Africa, Canada, Siberia, and the Arctic.Four most renowned organization that publish global surface temperature dataset are Remote Sensing Systems (RSS) at University of Alabama- Huntsville, NOAA's National Climatic Data 
Center (NCDC), NASA's Goddard Institute for Space Studies (GISS/ GISTEMP), and the University of East Anglia's Climatic Research Unit (CRU). In this study, the GISS dataset was used because of its established validation (Reynolds and Smith, 1994; Smith et al., 2008).

According to GISS analysis, the year 2011 was the 9th warmest because it had an extreme El Nino. Based on this understanding, it is essential to review both the direct and indirect influence of the Southern Oscillation (El Nino-La Nina cycle) and the solar cycle (Miguel et al., 1998). The severity of the ENSO varies with geographical regions. However, it was propounded in this study that there are unknown factors that influence ENSO. In this paper, 85 year's dataset were analyzed to establish known facts and new hypothesis. This research focused on Mozambique. Logically, the result also extends to Southern Africa.

Fluctuations in Southern Africa's seasonal rains and surface temperature were linked to the El Niño Southern Oscillation. There are two types of El Nino impact on the precipitation system of Southern Africa (Ropelewski and Halpert, 1987) i.e. Eastern equatorial Africa precipitation system (leading to increased rainfall) and South Eastern Africa precipitation system (leading to decreased rainfall). This was the scientific explanation for major droughts that occurred in 1983, 1992, 1994 and 1995 (Benson and Edward, 1998). In Mozambique, the severe drought that occurred between 1991 and 1992 were related to ENSO (Epstein and Chikwenhere, 1994). In the second and third section of this study, it was established that signs of the extreme El Niño events that led to the aforementioned drought is replaying in recent times.

Records show that the last two severe droughts in Mozambique occurred during the El Niño events of 1982-84 and 1991-92. The latter prolonged to 1995 (Msengezi, 1992). The most affected provinces were Inhambane, Gaza, and Maputo (southern region of Mozambique). Forecasting ENSO in southern Africa has only achieved a lead time of up to one year (Cain et al., 1996). The surface temperature dataset used for this research were obtained in Inhambane between 1931 and 2015 . Inhambane is located on the coast of southern Mozambique. It has an area of $68,615 \mathrm{~km}^{2}$ and population of 1,412,349 (Figure 1). The objective of this study is to observe the current trend of extreme surface temperature trends over the study area.

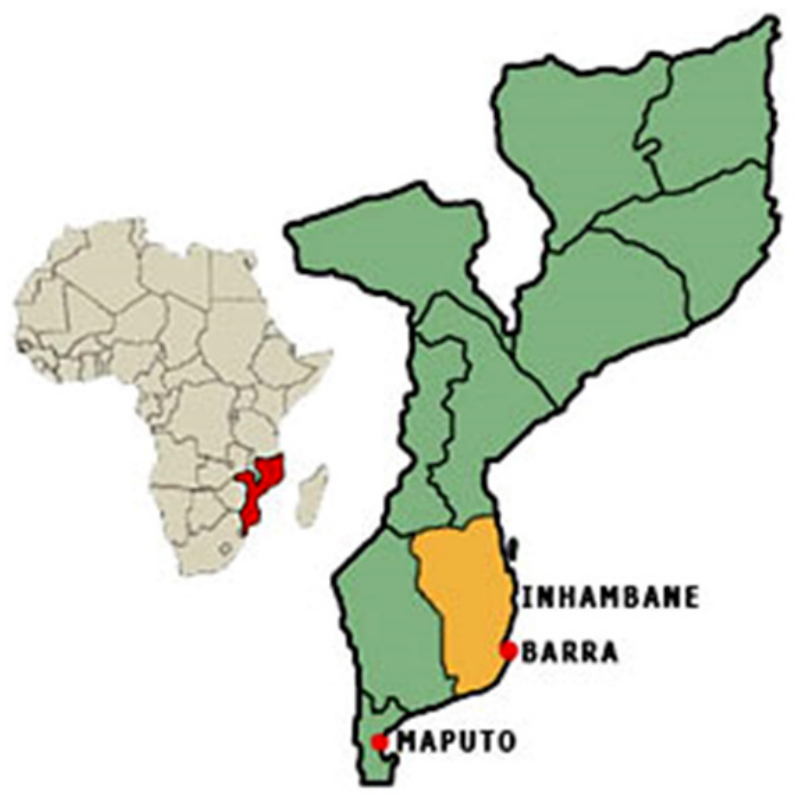

Figure 1: Map of Inhambane-Mozambique (Unknown, 2017) 


\section{Methodology}

The surface temperature dataset from 1931-2015 were obtained from the GISS. The set-up and operational modalities of the GISS can be found in existing literatures (Hansen et al., 1999; Hansen et al., 2001). The computational analysis for 1931 was done to examine the effect of the predictive model from the variables obtained from the curve-fitting technique. The predictive calculations for 2, 5 and 10 years were carried-out to see if the dataset from 1931-1941 can be used to computationally predict events in a more specific and uniform pattern.

Secondly, the trends of the computational model were observed for three decades i.e. 1942-1943, 1953-1954 and 1965-1966. The objective of this technique is to observe the non-influenced southern oscillation years. This activity would help to comprehend the unknown factors that may exist in the study area. Hence, monthly analysis was carried-out for some selected months within 1931-1965. The months were November, October, September, May and March. These months are active months known for increased anthropogenic activities that lead to the release of greenhouse gases and aerosols into the environment (Emetere et al., 2016; Emetere, 2016). Hence, the second objective of this technique is to verify the influence of ENSO on the surface temperature of the research site. This was accomplished via an accurate estimation of percentages for each succeeding years.

Thirdly, the computational analysis for every decade beginning from 1931 to 2015 was investigated. This technique shed more insight on the different trends of surface temperature for a group of ten years within nine decades. The elementary statistics were used for each group to identify the most active group. This idea was initiated to refute or strengthen the idea of southern oscillation on the surface temperatures in southern Africa.

Lastly, a statistical analysis was carried-out to strengthen or clarify any observations that would be obtained from the aforementioned techniques. In the statistical analysis, the thermal distribution were considered i.e. beta probability distribution (Weisstein, 2009) as shown in equations 1 :

$$
x=\frac{T_{j}-T_{\text {low }}}{T_{\text {high }}-T_{\text {low }}}
$$

$T_{j}$ is the inputted temperature, $T_{\text {low }}$ is the lowest temperature in the year/month, $T_{\text {high }}$ is the highest temperature in the year/month. This technique was adopted for the year 2000-2015. A linear regression was carried-out. Alongside the linear regression, the residual analysis was done to further understand why 2011 was regarded as the ninth warmest year and the possibility of obtaining a warmer year over the study area.

\section{Results and Discussion}

The general trend of 1931 was higher temperature between April and September. The highest surface temperature (ST) was observed in the month of June (Figure 2a). Using the polynomial curve fitting, the coefficient of the polynomic equation was obtained. The coefficient that was obtained was used to calculate the surface temperature for two years (Figure 2b). From the result, it was expected that the early months in 1932 may have higher temperatures than 1933. 

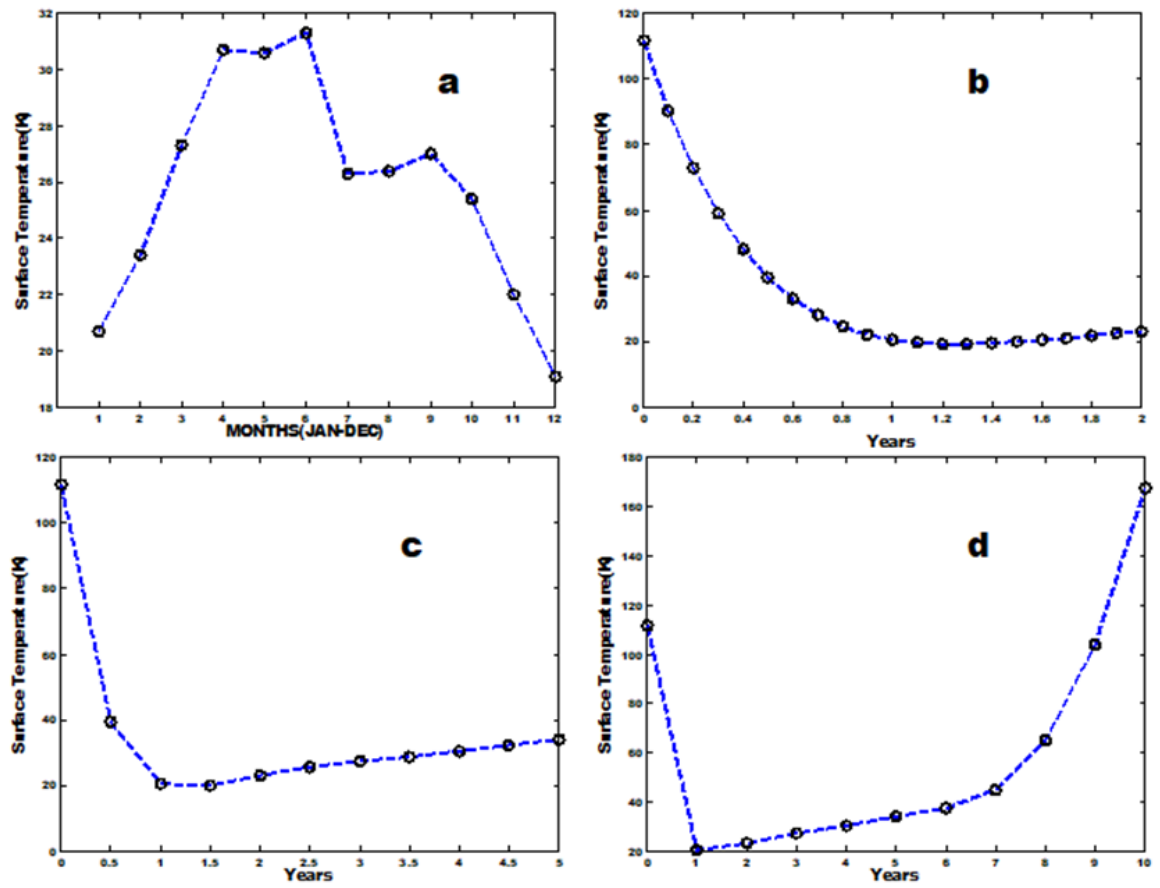

Figure 2: Surface temperature in 1931 (a) monthly performance for 1931 (b) two years prediction of surface temperature (c) five years prediction of surface temperature (d) ten years prediction of surface temperature

The projection was accurate i.e. compared with the GISS dataset. In year 1932, the minimum and maximum temperature was $14.4{ }^{\circ} \mathrm{C}$ and $35.3{ }^{\circ} \mathrm{C}$ respectively; while in 1933 , the minimum and maximum temperature was $12.0{ }^{\circ} \mathrm{C}$ and $32.1{ }^{\circ} \mathrm{C}$ respectively. The projection was then extended to 5 years (Figure 2C). It was expected that after the initial depreciation in 1933, the surface temperature would appreciate steadily till 1936. This projection was also validated by the GISS dataset whose surface temperatures for 1933, 1934, 1935 and 1936 were $32.1{ }^{\circ} \mathrm{C}, 32.4{ }^{\circ} \mathrm{C}, 34.8{ }^{\circ} \mathrm{C}$ and $34.5{ }^{\circ} \mathrm{C}$ respectively. Hence, the polynomial projections were adjudged accurate from the initial estimations.

Lastly, the calculation and simulation for a ten years' event using the polynomial technique is shown in Figure $2 \mathrm{~d}$. It shows that a continuous rise is expected-such that the highest surface temperature would be in 1940. Though the GISS dataset showed that the highest surface temperature was in $1938\left(34.7{ }^{\circ} \mathrm{C}\right)$, the surface temperature for the year 1940 was $34.6{ }^{\circ} \mathrm{C}$. Hence, we expect some level of inadequacies when we use the computational studies alone. However, the computational studies show that yearly rise of $11.2 \%$ is expected if there are no major climatic perturbations.

Upon this understanding, we examined three decades to see if the projections are true. From the general trend shown in Figure 2a, we expect that the surface temperature changes every May. This is because of the raining season. Hence, seventeen months' dataset were considered because emphasis on the month of May. The results in 1942-1943 (Figure 3a), 1953-1954 (Figure 3b) and 19651966 (Figure 3c) showed that the surface temperatures were reduced by $3.13 \%, 3.13 \%$ and $6.45 \%$ respectively. This results supports that there are influences of climatic forces on the surface temperature.

To further understand the differentials changes over eighty-five years, we analyzed each month between 1931-2015 as an entity. January had the lowest standard deviation (0.9582) and coefficient of 
variation (0.07002); September had the highest standard deviation (4.504); October had the highest coefficient of variation (o.19631). The maximum surface temperature for each month and the corresponding year is given as $16{ }^{\circ} \mathrm{C}$ (January - 1990), $21.4{ }^{\circ} \mathrm{C}$ (February - 2006), 26.3 ${ }^{\circ} \mathrm{C}$ (March - 2010), $32.7{ }^{\circ} \mathrm{C}$ (April - 2010), 35.2 ${ }^{\circ} \mathrm{C}$ (May - 1978), $36.2{ }^{\circ} \mathrm{C}$ (June - 2012), $34.8{ }^{\circ} \mathrm{C}$ (July - 2002), $32.4{ }^{\circ} \mathrm{C}$ (August 1987), $31.2{ }^{\circ} \mathrm{C}$ (September - 1987), $28.7{ }^{\circ} \mathrm{C}$ (October - 1951), $22.1{ }^{\circ} \mathrm{C}$ (November - $1977 \& 2011$ ) and $17.6{ }^{\circ} \mathrm{C}$ (December - 2013).

The mean surface temperature for January, February, March, April, May, June, July, August, September, October, November and December are given as $13.68{ }^{\circ} \mathrm{C}, 16.52{ }^{\circ} \mathrm{C}, 21.7{ }^{\circ} \mathrm{C}, 28.06{ }^{\circ} \mathrm{C}, 32.13$ ${ }^{\circ} \mathrm{C}, 32.98{ }^{\circ} \mathrm{C}, 30.43{ }^{\circ} \mathrm{C}, 29.31{ }^{\circ} \mathrm{C}, 28.29{ }^{\circ} \mathrm{C}, 24.82{ }^{\circ} \mathrm{C}$ and $19.58{ }^{\circ} \mathrm{C}$ respectively.
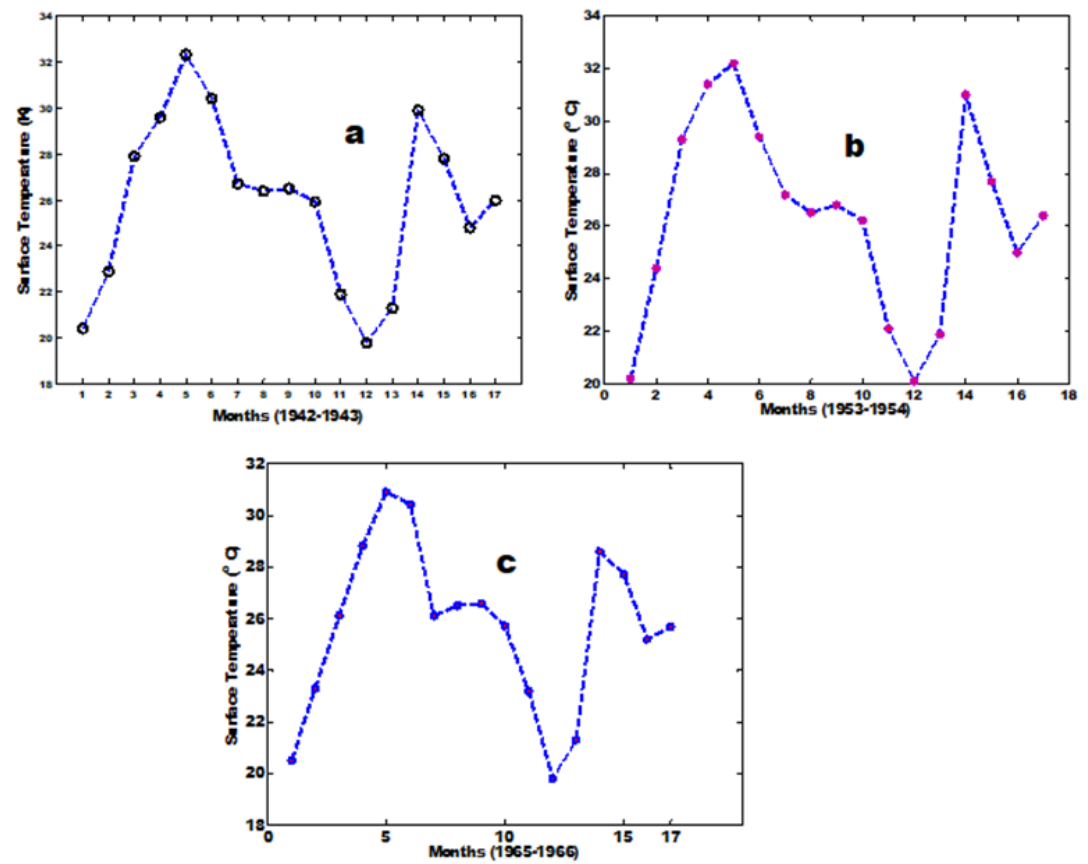

Figure 3: Surface temperature validation (a) for 1942-1943 (b) for 1953-1954 (c) for 1965-1966

The years between 1931-2015 were then divided into a group of ten years (Figures 4a - i) and were statistically analyzed (Table 1). A limit for the maximum temperature was set at $>34{ }^{\circ} \mathrm{C}$. The cumulative average of all the years is given at $24.38^{\circ} \mathrm{C}$. Hence, the formula below was adopted to calculate the percentage increase or decrease of mean surface temperature:

$$
p=\frac{T-24.38}{24.38} \times 100 \%
$$

where $\mathrm{T}$ is the temperature for each year.

Figure 4a represents the ST from 1931-1940. Seven out of the ten years had a maximum temperature that was above the set limit. This means that a major climatic event might have occurred within 1931 to 1940. The maximum percentage increase occurred in 1938 i.e. $2.47 \%$. The average increase in temperature within the given year was $1.69 \%$. From simulation, the year 1940 had the maximum distribution with a slight temperature increase of $0.59 \%$. The high surface temperatures that span seven years was as a result of the tropical cyclone (TC) and intensities that lasted within the period of 1931 to 1943. In addition to the known facts, strong El Niño events occurred in 1931 and 1932. Also, strong La Niña events occurred in 1933, 1934, 1938 and 1939 (NOAA, 2017). Hence, 1933 and 1934 had a reduced 
surface temperature of $3.43 \%$ and $0.52 \%$ respectively (see Table 1 ). This shows that the La Niño cycle that ought to span a minimum of 5 years maybe lower or higher at certain prevailing conditions.

Figure $4 \mathrm{~b}$ shows a group of ten years ranging from 1941 to 1950 . Within this range, eighth of the year had high surface temperature which is traceable to the tropical cyclone. The record for the year 1943 was surprisingly low compared to the other years within the group. The increased surface temperature from 1947 through to 1950 was adduced to hurricane activities that occurred from 1944 through 1953 (Goldenberg et al., 2001). The cumulative increase in surface temperature within 1941 to 1950 is given as $10.12 \%$. The year 1941 had the highest surface temperature increase of $5.4 \%$. This result may be an extensive influence of the tropical cyclone. All the years between 1941 and 1949 are almost of same magnitude except for 1950 that had a reduced surface temperature of $2.1 \%$. The distribution for all the years (Figure 4c) was almost uniform with an increase in the surface temperature at about $20.5 \%$. Between 1951-1960, six out of ten years had maximum surface temperature. This result coincides with the El Nino activities that occurred in 1951, 1957, 1958 and 1959 (NOAA, 2017). El Nina occurred between 1954 and 1956. We believe that this event sustained the increase in the surface temperature except for 1957 where it reduced by $1.13 \%$. The highest surface temperature for October in the eighty-five years' analysis was in 1951. This means that the El Nino in 1951 was the most severe in eighty-five years.
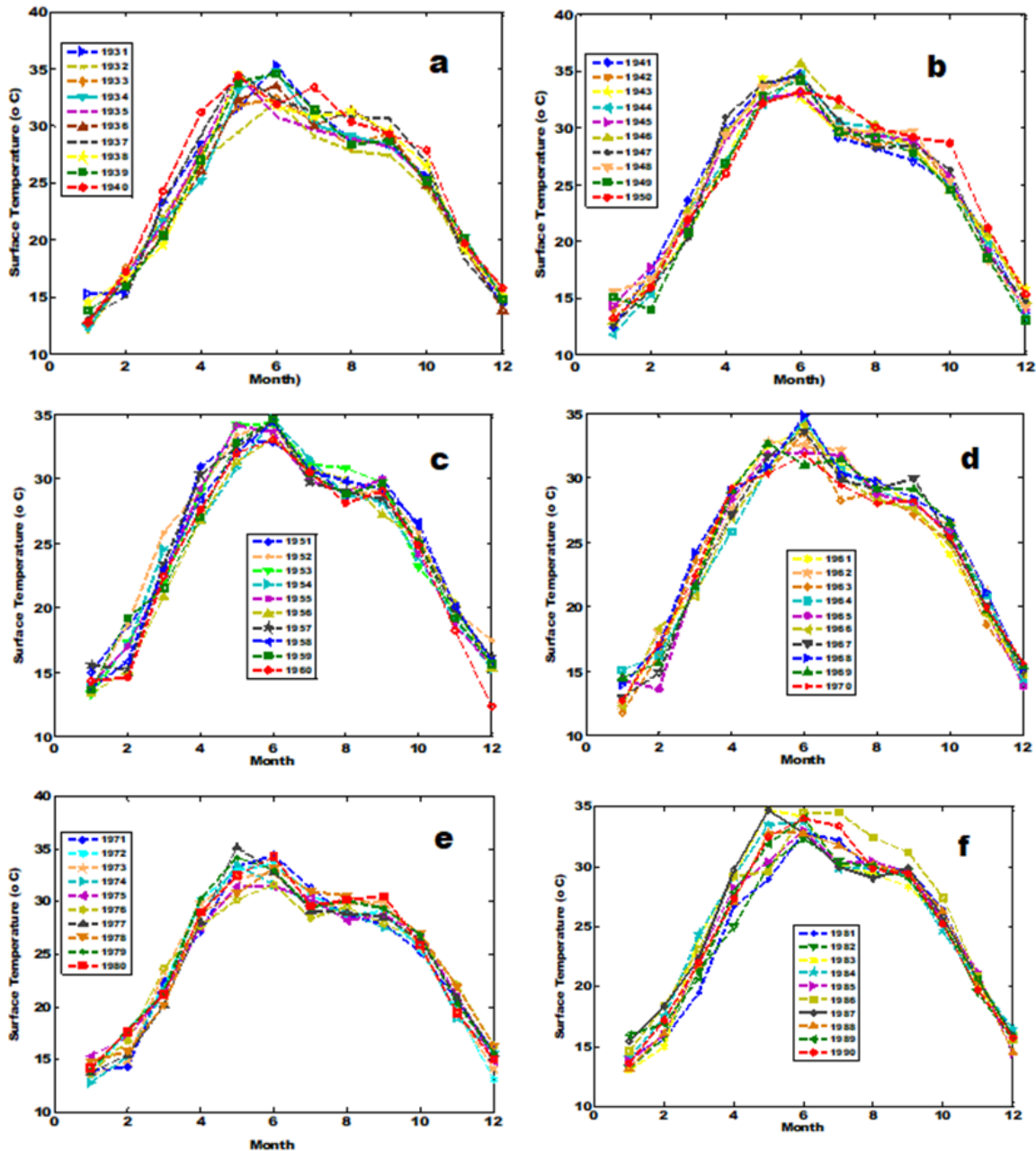

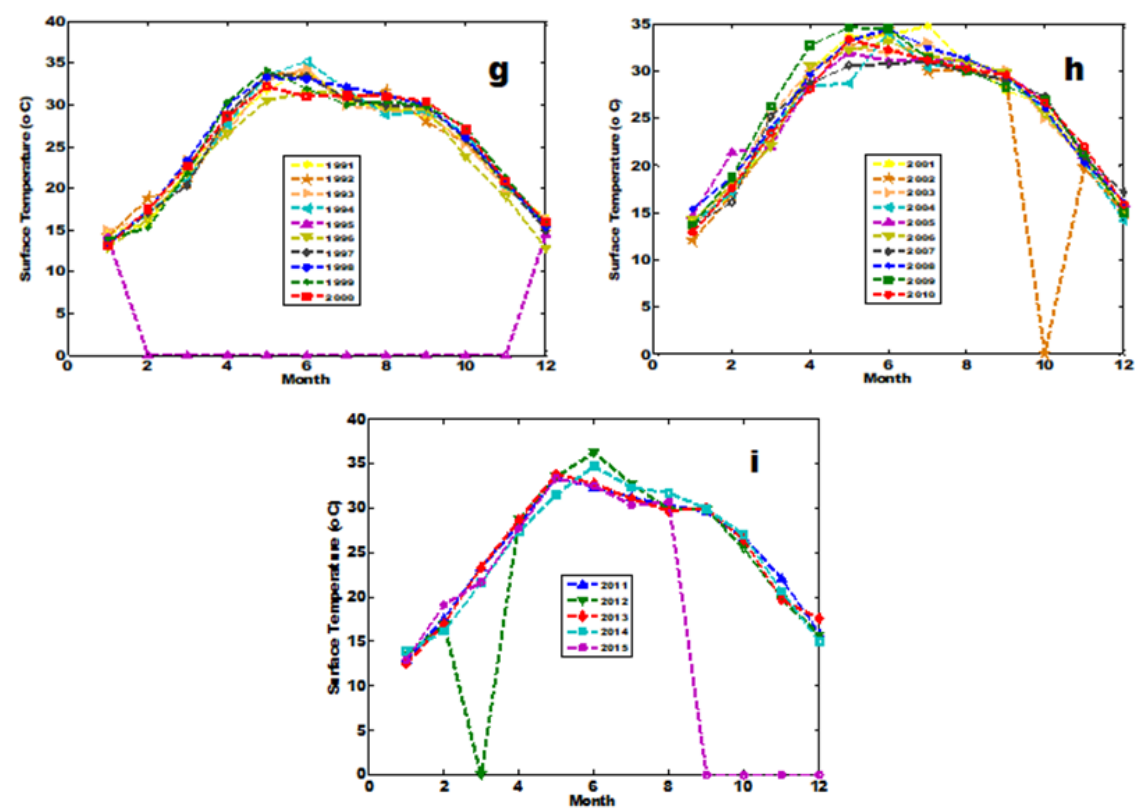

Figure 4: decade grouping of surface temperature performance between 1931 and 2015 (a) analysis from 1931-1940 (b) analysis from 1941-1950 (c) analysis from 1951-1960 (d) analysis from 1961-1970 (e) analysis from 1971-1980 (f) analysis from 1981-1990 (g) analysis from 1991-200o (h) analysis from 20012010 (i) analysis from 2011-2015

The surface distribution between the year 1961 and 1970 is almost uniform (i.e. with a cumulative decrease of $2.58 \%$ ). Only three years within $1961-1970$ had a maximum surface temperature $\left(>34{ }^{\circ} \mathrm{C}\right)$ i.e. 1965, 1967 and 1969. Also, only four years experienced an increase in surface temperature i.e. 1962 (o.18\%), 1963 (0.67\%), $1969(2.88 \%)$ and $1970(1 \%) .1967$ had the lowest cumulative surface temperature decrease of $1.5 \%$. Like the previous decade, the surface distribution between the year 1971 and 1980 was almost uniform (i.e. with a cumulative increase of 9.89\%). Like the previous decade, only three years had maximum surface temperature with an increase percentage given as 1974 (o.84\%), 1978 (o.89\%) and 1980 (3.4\%). However, it was observed that some years had maximum surface temperature with reduced cumulative performance. For example, 1965 was one of the years of high surface temperature with a reduced percentage of $0.23 \%$ (see Table 1 ). The records of the El Nino showed that it occurred in the year 1971, 1972, 1976, 1977 and 1978; while the El Nina occurred in 1971, 1974, 1975 and 1976 (NOAA, 2017). The highest surface temperature for May and November within eighty-five years occurred in 1978 and 1977 respectively. This means that the El Nino was most severe in eighty-five years in the months of May and November. Also, it was observed statistically that the years within 1961-1980 had low influence of climatic perturbations (Figure 4d,e).

The years i.e. 1981-1990 had a non-uniform surface temperature distribution as shown in Figure 4f. The surface temperature increased within the given years to $21.1 \%$. This group had the most statistical relevance. For example, the highest mean, minimum and maximum temperature was found in 1987 and 1988; five out of ten years had surface temperature above $34{ }^{\circ} \mathrm{C}$; four out of the five years had considerably high minimum and maximum surface temperature (Table 1). Unfortunately, 1986 do not have statistical relevance because it had high mean surface temperature with different feature from the other years (Figure 4f). It was observed that almost the same trend exists between 1991-200o. The cumulative surface temperature increase was about $19.3 \%$. More significant is the scanty data 
that was noticed in 1996 (Figure 4g) i.e. leading to an all-time low of about $70 \%$. Thus, only that year was discarded from the cumulative analysis of the group of years.

Table 1a: Statistical Analysis of the surface Temperature 1931-1970

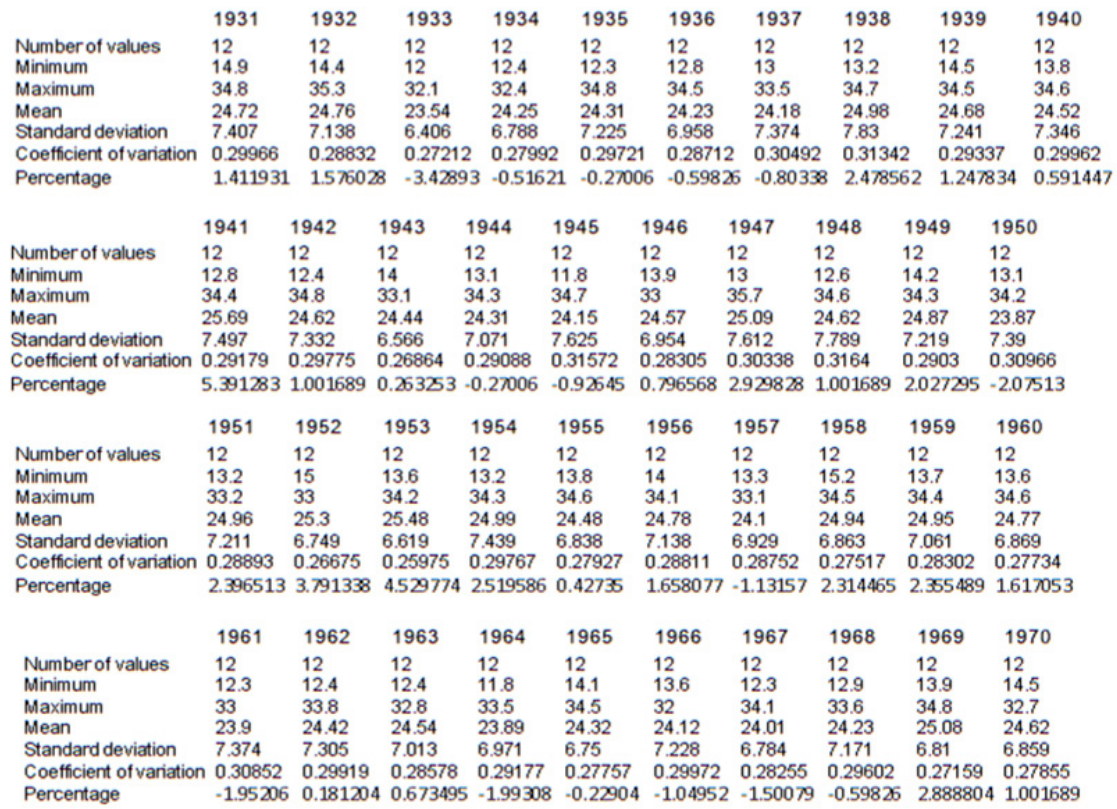

Table 1b: Statistical Analysis of the surface Temperature 1971-201åo

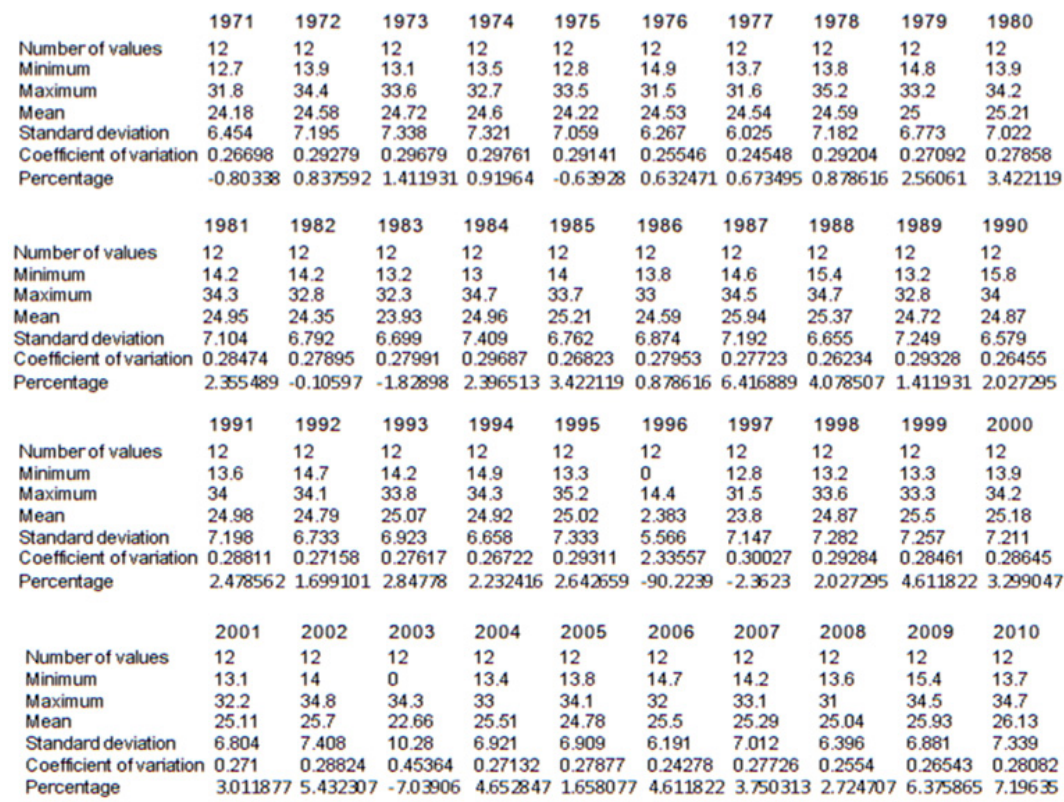


Table 1: Statistical Analysis of the surface Temperature 1971-2010

Number of values

Minimum

Maximum

Mean

Standard deviation

Coefficient of variation

Percentage

2011
12
12.9
33.4
25.29
6.862
0.27132
3.750313

2012
12
0
36.2
23.5
10.57
0.44961
-3.59303

$\begin{array}{cc}2014 & 2015 \\ 12 & 12 \\ 13.8 & 0 \\ 34.7 & 33.3 \\ 25.12 & 17.35 \\ 7.418 & 14.09 \\ 0.29535 & 0.81193 \\ 3.052901 & -28.8229\end{array}$

Table 2: Statistical Analysis of the surface Temperature 2001-2015

\begin{tabular}{|c|c|c|c|c|c|}
\hline Type & $P_{1}$ & $\mathbf{P}_{2}$ & STD $_{1}$ & STD $2_{2}$ & $\mathbf{R}^{2}$ \\
\hline $\mathrm{S}_{1} \& \mathrm{~S}_{2}$ & 0.97635 & -0.051338 & 0.3562 & 0.3561 & 0.98 \\
\hline $\mathrm{S}_{1} \& \mathrm{~S}_{3}$ & 0.54356 & 0.31885 & 0.3562 & 0.2997 & 0.54 \\
\hline $\mathrm{S}_{1} \& \mathrm{~S}_{4}$ & 0.97424 & 0.0052584 & 0.3562 & 0.3531 & 0.97 \\
\hline $\mathrm{S}_{1} \& \mathrm{~S}_{5}$ & 0.92925 & -0.043178 & 0.3562 & 0.3403 & 0.93 \\
\hline S1\&S6 & 0.1919 & $1.558 \mathrm{e}-08$ & 0.3562 & 0.3579 & 0.99 \\
\hline $\mathrm{S}_{1} \& \mathrm{~S}_{7}$ & 1.0288 & -0.05998 & 0.3562 & 0.371 & 1 \\
\hline S1\&S8 & 1.0167 & 0.018375 & 0.3562 & 0.3676 & 1 \\
\hline S1\&S9 & 0.99271 & -0.073079 & 0.3562 & 0.3603 & 0.99 \\
\hline S1\&S10 & 0.94381 & -0.0013167 & 0.3562 & 0.3495 & 0.827 \\
\hline S1\&S11 & 0.93361 & 0.017501 & 0.3562 & 0.3347 & 0.93 \\
\hline$S_{1 \& S 12}$ & 0.63222 & 0.25169 & 0.3562 & 0.2919 & 0.63 \\
\hline $\mathrm{S}_{1 \& S_{13}}$ & 0.91304 & 0.021818 & 0.3562 & 0.329 & 0.91 \\
\hline $\mathrm{S}_{1 \& S_{14}}$ & 0.97984 & -0.074564 & 0.3562 & 0.3549 & 0.98 \\
\hline $\mathrm{S}_{1 \& S_{15}}$ & 0.59928 & 0.14425 & 0.3562 & 0.423 & 0.60 \\
\hline
\end{tabular}

The years 2000-2010 and 2011-2015 had the highest mean in eighty-five years (Table 1). The cumulative increase between 2000 and 2010 is given as $32.4 \%$ while the cumulative increase between 2011 and 2014 is given as $6.55 \%$ (Figure $4 \mathrm{~h}, \mathrm{i}$ ). The realities of climate change are more significant in recent years, hence, the regression analysis using the beta probability distribution was carried-out to estimate the minute changes expected.

The regression analysis for the entire outcome showed high correlation (Table 2). The residual plot for each of the regression analysis -alongside the regression plot is shown in Figures 5a to n. The undulating nature of the residual plot suggests high climatic disturbances. Figures $5 \mathrm{~b}, \mathrm{j}, \mathrm{k}$ and 1 had minimum perturbations. These results do not have any unique relation to the surface temperature (ST) statistically. However, the residual plots were related to the strong El Niño weather cycle and climate change [17]. For example, the minimum perturbations were noticed in 2001 (Figure 5b), 2010 (Figure 5j), 2011 (Figure 5k) and 2012 (Figure 5l) which had very strong El Nino influence.

Figures $5 \mathrm{~h}, \mathrm{i}$ and $\mathrm{n}$ had the most undulating features in the fifteen years' analysis. The years involved were 2008, 2009 and 2015 whose increase in ST is given as $2.7 \%, 6.4 \%$ and $5.2 \%$ respectively. Also, it was established that the signatures of severe ENSO that occurred within 1938-1950 is replaying within 2000-2015. Hence, life-form should expect a severe weather conditions in the nearest future. Already, the study site had experienced intense drought at earliest stages of 2015 to mid 2016 agricultural season. Hence, highest undulating features of residual plots simply herald a tortuous period for life forms. Though scientists claimed that drought is basically caused by El Nino events of the last 50 years, this research establishes that a severe weather conditions have been sustained over the research site for over 85 years. 

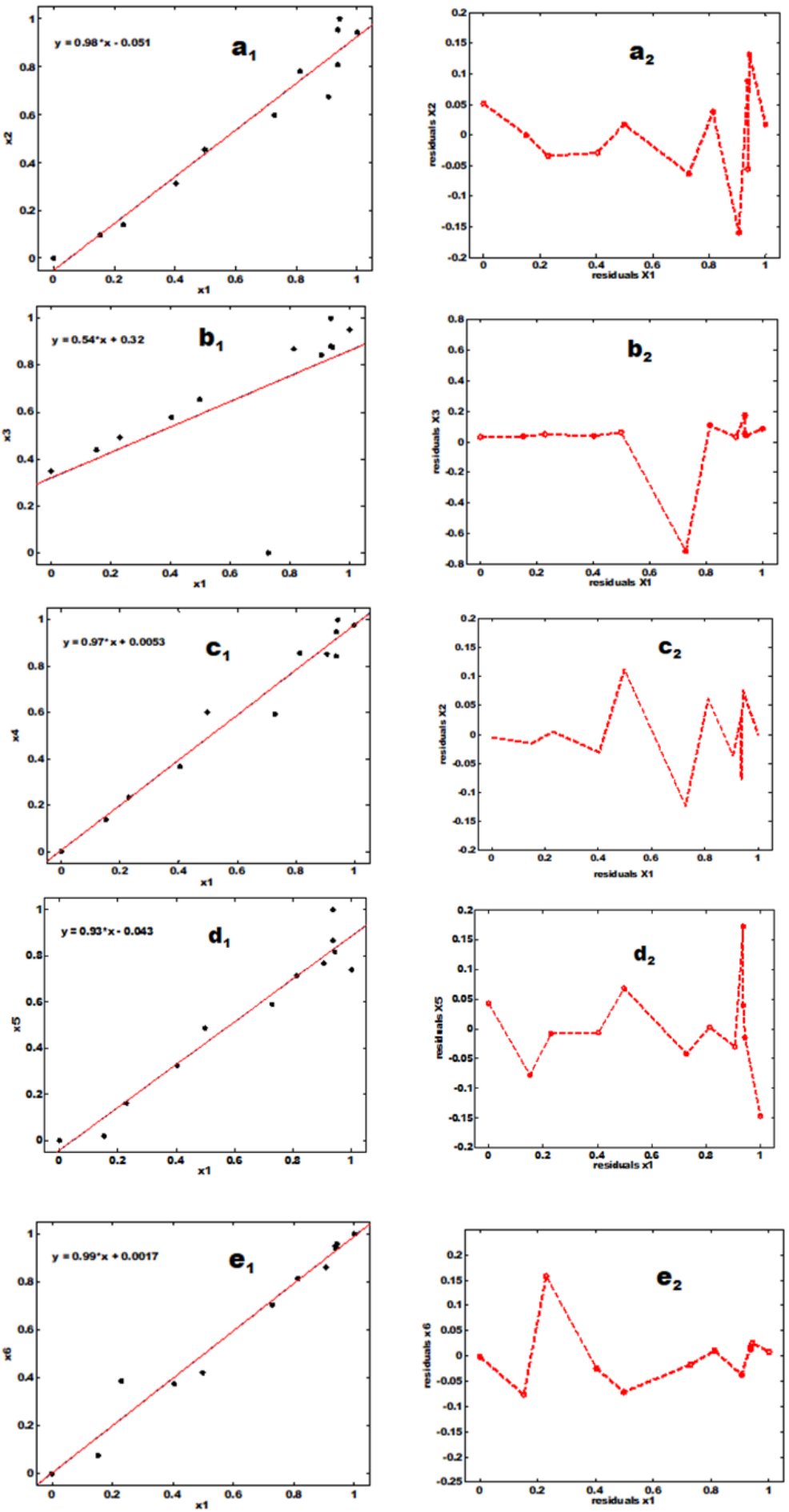

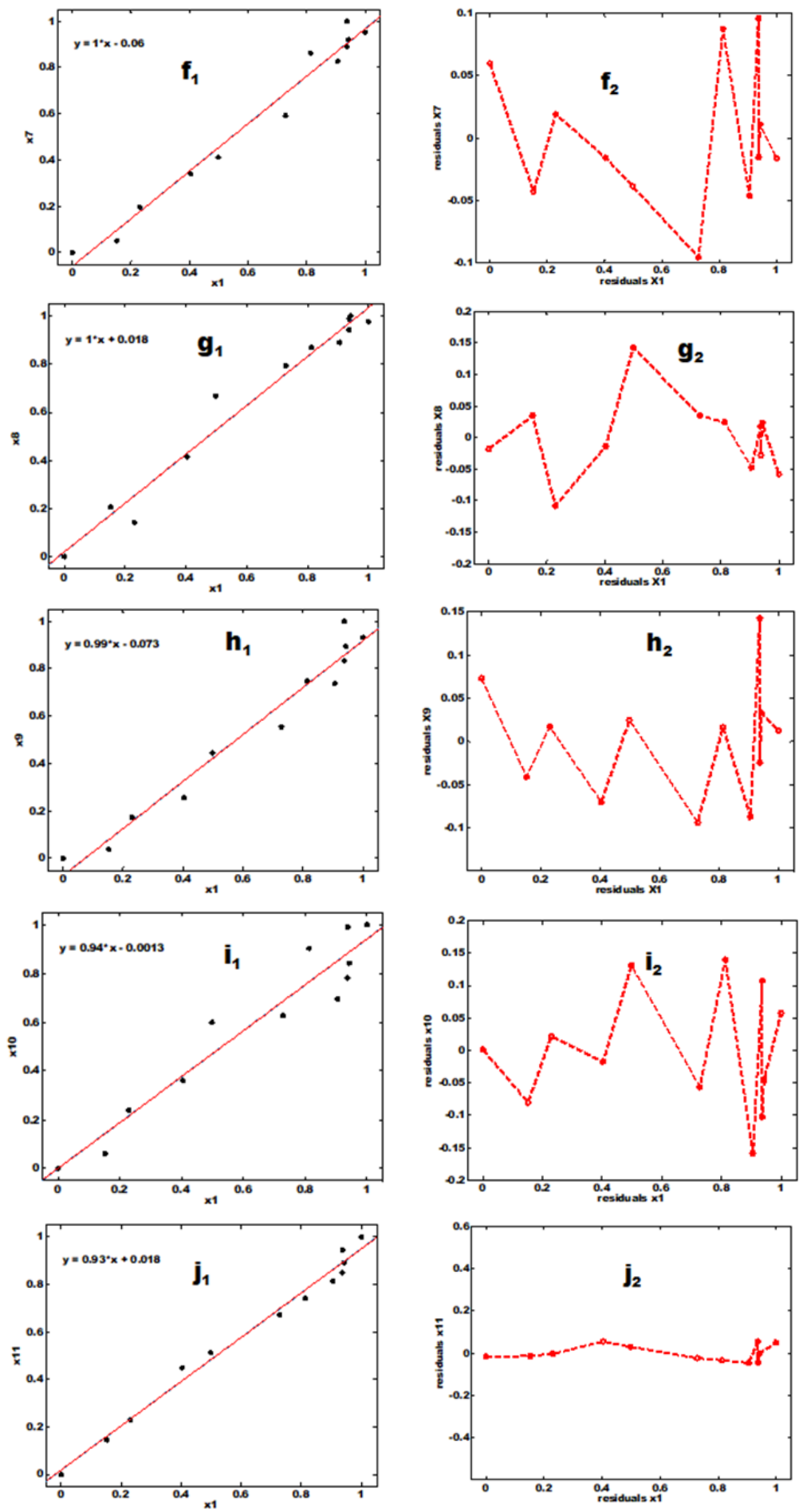

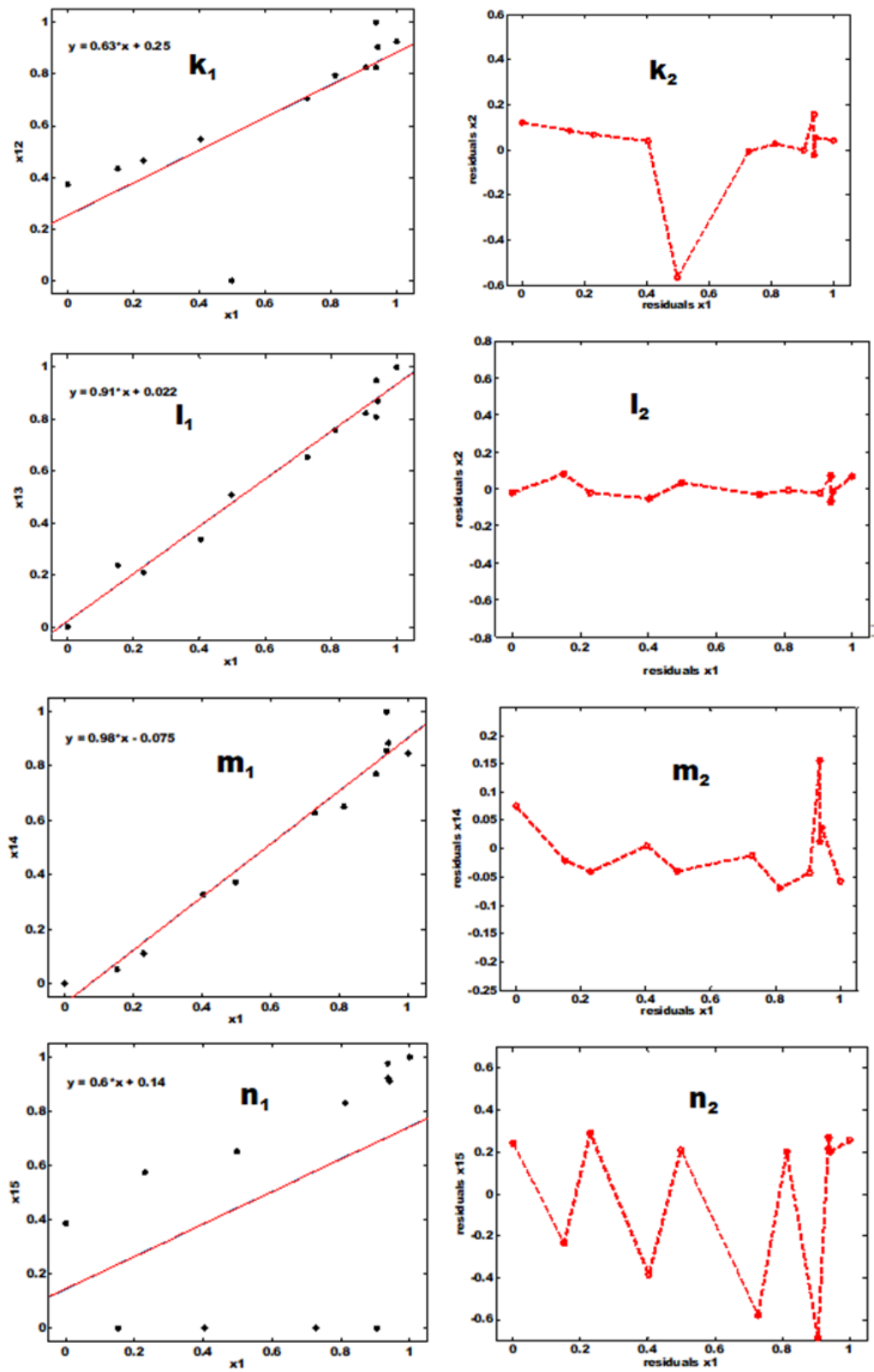

Figure 5: The regression analysis and residual plots for surface temperature events from 2001-2015.

\section{Conclusions}

From the above analysis, droughts over Mozambique and some parts of Southern Africa, is not caused by certain extreme ENSO but a sustained severe weather conditions. Hence, drought over the research site is a product of consistent severe weather conditions that influence certain atmospheric 
conditions that leads to severe El Nino. Also, it was observed that the surface temperature signatures of severe ENSO that occurred within 1938-1950 are replaying within 2000-2015. Hence, severe ENSO may occur in the nearest future.

The years 2000-2010 and 2011-2015 had the highest mean in eighty-five years (Table 1). The cumulative increase between 2000 and 2010 is given as $32.4 \%$ while the cumulative increase between 2011 and 2014 is given as $6.55 \%$. The meteorological implication on the location is more droughts in the coming decade except serious palliative measures to reduce its effect are urgently executed.

\section{Acknowledgement}

The authors appreciate the host institution.

\section{Reference}

Benson, Charlotte and Edward Clay. (1998). The Impact of Drought on Sub-Saharan African Economies: A Preliminary Examination. World Bank Technical Paper , 401. Washington, D.C.: World Bank.

Cane MA, Zebiak SE, Dolan SC. (1986) Experimental forecasts of El Niño. Nature, 321:827-832.

Christy, J. R., R. W. Spencer, and W. D. Braswell. (200o), MSU tropospheric temperatures: Dataset construction and radiosonde comparisons, J. Atmos. Oceanic Techno., 17, 1153-1170

Douglass David H., Benjamin D. Pearson, and S. Fred Singer (2004). Altitude dependence of atmospheric temperature trends: Climate models versus observation, Geophysical Research Letters, 31, L13208, doi:10.1029/2004GLo20103

Emetere Moses E., Akinyemi M.L. \& Akinwumi S.A. (2016) Aerosols Loading Trends And Its Environmental Threats Over Cotonou-Benin, Nature Environment and Pollution Technology, 15 (3), 1111-1116

Emetere, Moses Eterigho, (2016) Statistical Examination Of The Aerosols Loading Over Mubi-Nigeria: The Satellite Observation Analysis, Geographica Panonica, 20(1), 42-50

Epstein PR, and Chikwenhere GP. (1994) Environmental factors in disease surveillance. Lancet, 343, 1440-41.

Goldenberg, S.B., C.W. Landsea, A.M. Mestas-Nunez, and W.M. Gray, (2001). The recent increase in Atlantic hurricane activity: Causes and implications. Science, 293: 474-479.

Hansen, J., R. Ruedy, M. Sato, and K. Lo, (2010) Global surface temperature change. Rev. Geophys., 48, RG40o4, doi:10.1029/2010RGooo345.

Hansen, J., R. Ruedy, J. Glascoe, and M. Sato. (1999). GISS analysis of surface temperature change. J. Geophys. Res. 104, 30997-31022.

Hansen, J., R. Ruedy, M. Sato, M. Imhoff, W. Lawrence, D. Easterling, T. Peterson, and T. Karl. (2001). A closer look at United States and global surface temperature change. J. Geophys. Res. 106, 23947-23963.

Miguel Aragón, Avertino Barreto and Paul R. Epstein. (1998) Drought and Health Implications in Mozambique, Medicine \& Global Survival, 5 (1), 42-49

Msengezi T. (1992) The drought situation in Mozambique. Southern Africa News Features. May 1992:1-2.

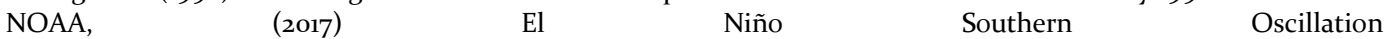
https://www.esrl.noaa.gov/psd/enso/climaterisks/years/top24enso.html (14th February, 2017)

Reynolds, R.W. and T.M. Smith, (1994). Improved global sea surface temperature analyses, Journal of Climate, 7: 929-948

Ropelewski C.F. and Halpert M.S. (1987) Global and regional scale precipitation patterns associated with the El Niño / Southern Oscillation (ENSO). Monthly Weather Review, 115, 1606-1626

Smith, T. M., Reynold, R.W., Peterson, T.C.., and Lawrimore, J., (2008) Improvements to NOAA's Historical Merged Land-Ocean Surface Temperature Analysis (1880-2006). J.Climate, 21, 2283-2296, http://dx.doi.org/10.1175/2007JCLI2100.1.

Unknown (2017). http://www.inhambane.co.za/location.htm, (accessed 19/02/2017)

Weisstein E. W., (2009). Beta distribution. From Mathworld-A wolfram web resource. http://mathworld.wolfram.com/BetaDistribution.html (accessed 9th December, 2016) 